\title{
Insights about Fracture Conductivity Damage in Shale Formation
}

\author{
Bin Yang ${ }^{1,2}$, Jie $\mathrm{Xiao}^{3}$, Jing $\mathrm{Li}^{4}$, Chengliang $\mathrm{Li}^{4}$, Hongzhi Shao ${ }^{4}$ \\ ${ }^{1}$ Coresponding author, email: info@ smartpetrochem.com \\ ${ }^{2}$ LiaoDong Field Operations LLC (CNOOC TianJing Branch) \\ ${ }^{3}$ Holding Energy Petroleum Engineering (BeiJing) Co.,Ltd. \\ ${ }^{4}$ Northeast Petroleum University
}

\begin{abstract}
Hydraulic fracturing has been the most efficient treatment option for exploitation of shale reservoirs. However due to intrinsic properties of shale formation, fracture conductivity damage usually occurs through multi mechanisms. To minimize the fracture conductivity damage, extensive analysis should be conducted regarding to the properties of shale formations, properties of fracturing fluids and properties of proppants. Clay swelling, fines migration, proppant diagnosis, proppant crushing, and proppant embedment are the most important factors that affect fracture conductivity and well productivity over a long production time. Once damage occurs, optional remediation plans should be conducted to minimize the damaging effect.
\end{abstract}

Keywords: Fracture Conductivity; Formation Damage; Shale Formation; Proppant

\section{INTRODUCTION}

Shale reservoir has been the reason for significant increase of hydrocarbon production in recent years. It is estimated that more than $50 \%$ of natural gas will be produced by 2040 . The average recovery factor in shale formations varies from 15 to $35 \%$. In the exploitation of shale reservoir, optimization of completion technology yields most investment returns and most efficiency production of shale reservoir. Hydraulic fracturing treatment has been the main production technique for shale reservoirs. The purpose of hydraulic fracturing is to create high conductivity fractures to recover oil and gas [15].

However, the impairment of fracture conductivity in shale reservoir leads to rapid production decrease rate and low recovery factor [6]. Any formation damage on fracture conductivity is an undesirable both in operation scale and in economic aspect. Formation damage on fracture conductivity is not necessarily reversible. And it is always better to avoid than to remediate it.

A complete understanding of the petrophsical, mechanical, and mineralogical properties of shale is essential to understand the fracture conductivity damage in shale formation and to optimize the hydraulic fracture operations [7-9]. This study provides analysis on fracture conductivity damage in shale formation, including the detection methods, causes and how to avoid the damage. Conclusions and suggestions are drawn based on those discussions.

\section{Fracture Conductivity in Shale Formation}

Numerous researches have been conducted on fracture conductivity. Studies show that high conductivity fractures are less affected by multiphase flow and can help fracturing past condensate blocks. Low conductivity fracture, on the other hand, will generate large pressure drop and lead to less effective fracture network and lower recovery factor. Fracture conductivity can be affected by many factors [10-12], including fracture face roughness, formation stress, water trapping, proppant, shear displacement, etc.

Shale formation is highly heterogeneous with matrix permeability in nano Darcy range. Hydraulic fracturing in shale formation needs to create massive fractures and expose large fracture surface areas so hydrocarbon can be transported to the wellbore. It is very challenging to achieve long lasting fracture conductivity in shale formation due to shale's mineralogy and mechanical properties, especially for soft, clay-rich shale formations. Prospective shale formation varies significantly in clay content and mechanical properties (Table 2), therefore requires different hydraulic fracturing strategy [13-16]. 
Bin Yang et al.

Table 2: Mineralogy by Weight Percent of Several North American Shales.

\begin{tabular}{|c|c|c|c|c|c|}
\hline & Eagle Ford & Barnett & Lower Bakken & Middle Bakken & Haynesville \\
\hline Calcite & 77 & 12 & 0 & 77 & 2 \\
\hline Quartz & 3 & 59 & 21 & 11 & 28 \\
\hline Pyrite & 6 & 2 & 13 & 1 & 5 \\
\hline Dolomite & 2 & 1 & 10 & 4 & 0 \\
\hline Illite-Smectite & 8 & 21 & 47 & 4 & 57 \\
\hline
\end{tabular}

The presence of rich clay content in shale formation can cause many potential formation damage problems, thus leading to fracture conductivity damage. Kaolinite tends to break apart and migrate. Chlorite is very sensitive to acid and oxygenated waters [17-19]. Illite leaches potassium ions and will become expandable clay and migrate with other fines. Smectite is highly expandable and can cause severe formation damage and even plugging. So the mineralogy of shale formation needs to be addressed carefully to take the varied properties of clay minerals into account when designing hydraulic fracturing treatments.

\section{Detection ANd Causes}

To effectively detect the fracture conductivity damage in shale formation, four methods are most deployed: production data comparison, well testing and pressure-transient analysis, and laboratory testing and wellbore examination. Lab testing is simple one. Reservoir cores with hydraulic fracturing fluids are tested under simulated reservoir conditions, including the in-site stress, pressure, temperature, and treatment parameters. The responses of reservoir cores can be used to evaluate the effectiveness or potential fracture damage in field operations. Wellbore examination is usually done through analysis on production logs an down hole video images [20-23].

As discussed above, the clay minerals in shale formation can cause formation damage to shale formation and therefore poise damage on fracture conductivity damage. Shale formation is very sensitive to aqueous fluids and hydraulic fracturing fluids tend to weaken shale formation. According to some studies, the fracture face matrix damage depends on properties of reservoir and properties of fracturing fluids. Properties of reservoir include porosity and permeability. The properties of fracturing fluids include its leak-off coefficient, spurt loss coefficient and viscosity [24-27]. Properties of shale formation determine the vulnerability of formation damage, while fluid properties controls the degree of the formation damage. Proppant embedment and deformation, is another significant damage to fracture conductivity. It reduces the fracture aperture and the crushed proppant hinder the flow path of hydrocarbon. Low Young's module orBrinell hardness often leads to high embedment damage and more fine productions.

\section{Mechanisms}

Mechanisms of fracture conductivity in shale formation can be due to clay swelling, fines migration, proppant diagnosis, proppant crushing, and proppant embedment. Those impairment mechanisms differ from one formation to another, and depends on many variables, including mechanical properties of shale formation, mineral content, temperature, proppant type, type of fracturing fluids and closure stress [28].

The stability of fracture conductivity in shale formation depends on transport processes, physical change and chemical change. Those processes are affected both by mechanical forces and physicchemical forces. Mechanical stresses refers to the pore pressure, overburden and lateral stresses, and the cementation bond stresses at inter granular point. Physic-chemical forces are the result of hydration and solution of clay minerals in shale formation. The forces are Born repulsion, the van der Walls attraction, and the hydration or swelling stress.

The most commonly used proppants are sand, beramic beads, resin-coated sand, and sintered bauxite. When the fracture walls close, the desirable proppant must be transported far down a created fracture surface. It depends on proppant setting, proppant transportation, and proppant diagenesis. Proppant must be chemical inert so that do not dissolve over the life of the fracture wall. Proppant should also be strong enough to not be crushed under the force of closure stresses [29, 30].

Compared with consolidated sandstones, shale formation maintain low elastic module and embedment of proppant (Figure 1) is severe. Studies show that it can reduce from 10 to $60 \%$ on fracture 
conductivity. And $20 \%$ reduction in fracture aperture can lead to more than $50 \%$ reduction in recovery factor [31].

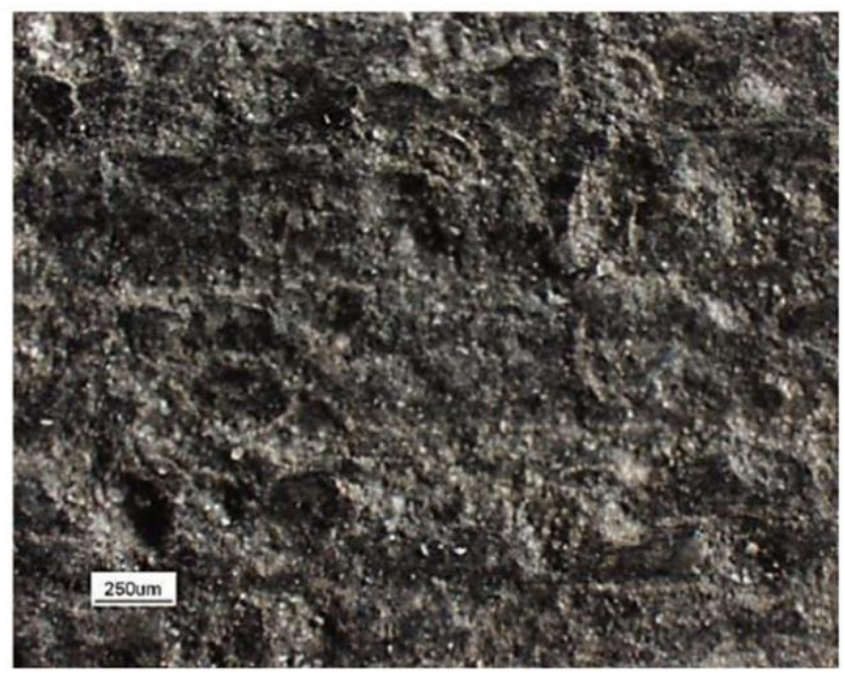

Figure1. Proppant embedment on fracture surface

Studies found that $88 \%$ of undamaged shale fracture conductivity is lost after water flows across the fracture surface due to the softening effect of shale surface. The average embedment depth is almost $50 \%$ of the median diameter.

\section{Solutions}

It is always better to take preventive measures than to remediate it. However, if the fracture conductivity damage occurs, some remediation can be taken [32]. Firstly, an effective remediation strategy should consist of treatment selection and design, treatment field testing, and routine field wide treatment applications. Then tasks are carried out to remediate fracture conductivity damage (Figure 2).

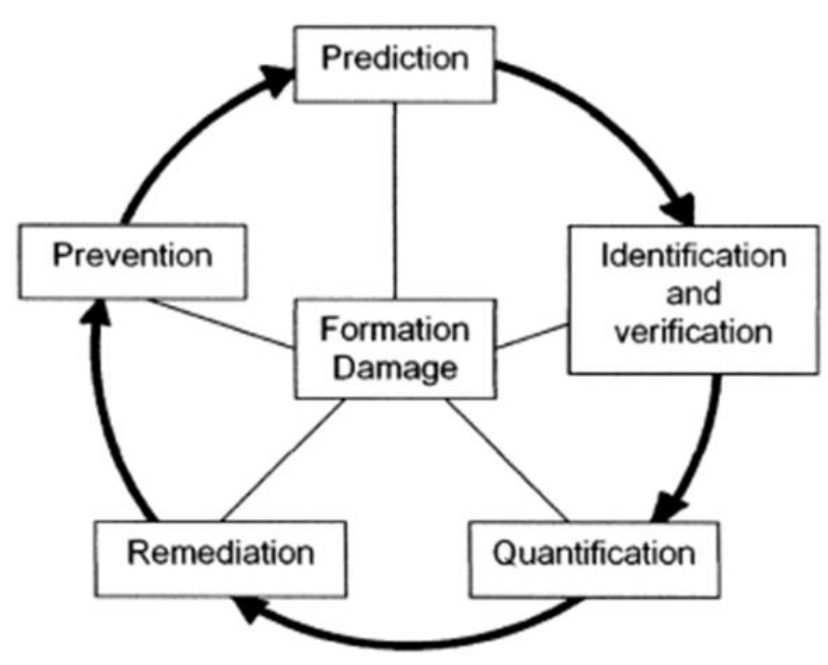

Figure2. Fracture conductivity damage remediation.

\section{Conclusions}

Based on above discussions, the following conclusions can be drawn:

- Fracture conductivity damage in shale formation can occur through multi mechanisms.

- To minimize potential fracture conductivity damage in shale formation, the fracturing fluids and proppant type need to be optimized before any field treatments.

- It is always better to prevent damage than to remediate it. However, optional remediation actions should be taken after damage on fracture conductivity has occurred. 


\section{REFERENCES}

[1] Alramahi, B., and Sundberg, M. I. 2012. Proppant Embedment And Conductivity of Hydraulic Fractures In Shales. American Rock Mechanics Association.

[2] He, J. 2011. Calcium Sulfate Formation and Mitigation When Seawater Was Used to Prepare Hcl-Based Acids, Texas AandM University.

[3] He, J. 2015. An Innovative Closed Fracture Acidizing Technique for Deep Carbonate Reservoirs Using Glda, Texas AandM University.

[4] Guo, B., Ganjy, E., Gao, D., and Ai, C. 2011. The Effect of Fracture Face Matrix Damage on Productivity of Fractured Wells with Infinitive and Finite Fracture Conductivities in Shale Gas Reservoirs. Society of Petroleum Engineers. doi:10.2118/143304-MS.

[5] Ji, L., and Geehan, T. 2013. Shale Failure around Hydraulic Fractures in Water Fracturing of Shale Gas. Society of Petroleum Engineers. doi:10.2118/167155-MS.

[6] He, J., Arensman, D., and Nasr-El-Din, H. 2013. Effectiveness of Calcium Sulfate Scale Inhibitors in Spent Hydrochloric Acid/Seawater System. Journal of Petroleum and Environmental Biotechnology 4 (159). doi:10.4172/2157-7463.1000159.

[7] He, J., Arensman, D., and Nasr-El-Din, H. 2013. Mitigation of Calcium Sulfate Precipitation in Spent Hydrochloric Acid/Seawater System. OTC Brasil 2013.

[8] Li, K., Gao, Y., Lyu, Y., and Wang, M. 2015. New Mathematical Models for Calculating Proppant Embedment and Fracture Conductivity. Society of Petroleum Engineers. doi:10.2118/155954-PA.

[9] He, J., Mohamed, I.M., and Nasr-El-Din, H.A. 2011. Mixing Hydrochloric Acid and Seawater for Matrix Acidizing: Is It a Good Practice? In SPE European Formation Damage Conference: Society of Petroleum Engineers. ISBN 1613991215.

[10] [He, J., Mohamed, I.M., and Nasr-El-Din, H.A. 2012. Mitigation of Calcium Sulfate Scale Formation When Seawater Is Used to Prepare Hcl-Based Acids. In SPE International Symposium and Exhibition on Formation Damage Control: Society of Petroleum Engineers.ISBN 1613991800.

[11] Lynn, J.D. and Nasr-El-Din, H.A. 1998. Evaluation of Formation Damage Due to Frac Stimulation of a Saudi Arabian Clastic Reservoir. Journal of Petroleum Science and Engineering 21 (3): 179-201.

[12] He, J., Mohamed, I.M., and Nasr-El-Din, H.A. 2013. Potential Formation Damage Due to Preparing Hcl Acids Using Seawater. Canadian Energy Technology and Innovation Journal 1(4): 56-63.

[13] He, J. and Nasr-El-Din, H. 2013. Petrochemistry and Chemical Engineering.

[14] Norman, L. R., Hollenbeak, K. H., and Harris, P. C. 1989. Fracture Conductivity Impairment Removal. Society of Petroleum Engineers. doi:10.2118/19732-MS.

[15] Kumar, R., He, J., and Nasr-El-Din, H. 2014. New Insights on the Effect of Oil Saturation on the Optimum Acid Injection Rate in Carbonate Acidizing. In SPE Improved Oil Recovery Symposium: Society of Petroleum Engineers.ISBN 1613993099.

[16] Olabode, A. O., and Radonjic, M. 2014. Diagenetic Influence of Aqueous CO2 on Fracture Conductivity of Shaly Rocks. Society of Petroleum Engineers. doi:10.2118/170892-MS.

[17] Kumar, R.P., He, J., and Nasr-El-Din, H. 2014. Effect of Oil Saturation on Acid Propagation During Matrix Acidization of Carbonate Rocks. In SPE Latin America and Caribbean Petroleum Engineering Conference: Society of Petroleum Engineers. ISBN 1613992904.

[18] Mohamed, I., He, J., and Nasr-El-Din, H.A. 2013. Effect of Brine Composition on CO2/Limestone Rock Interactions During CO2 Sequestration. Journal of Petroleum Science Research 2(1):14-26.

[19] Mohamed, I.M., He, J., Mahmoud, M. et al. 2010. Effects of Pressure CO2 Volume and the CO2 to Water Volumetric Ratio on Permeability Change During CO2 Sequestration. In Abu Dhabi International Petroleum Exhibition and Conference: Society of Petroleum Engineers. ISBN 1555633153. 
[20] Mohamed, I.M., He, J., and Nasr-El-Din, H.A. 2011. Carbon Dioxide Sequestration in Dolomite Rock. In International Petroleum Technology Conference: International Petroleum Technology Conference. ISBN 1613991487.

[21] Pedlow, J., and Sharma, M. 2014. Changes in Shale Fracture Conductivity due to Interactions with Water-Based Fluids. Society of Petroleum Engineers. doi:10.2118/168586-MS.

[22] Mohamed, I.M., He, J., and Nasr-El-Din, H.A. 2011. Permeability Change During CO2 Injection in Carbonate Aquifers: Experimental Study. In SPE Americas EandP Health Safety Security and Environmental Conference: Society of Petroleum Engineers. ISBN 1555633285.

[23] Mohamed, I.M., He, J., and Nasr-El-Din, H.A. 2011. Permeability Change During CO2 Injection in Carbonate Rock: A Coreflood Study. In SPE Production and Operations Symposium: Society of Petroleum Engineers. ISBN 1555633412.

[24] Mohamed, I.M., He, J., and Nasr-El-Din, H.A. 2011. Sulfate Precipitation During CO2 Sequestration in Carbonate Rock. In SPE Project and Facilities Challenges Conference at METS: Society of Petroleum Engineers. ISBN 1555633234.

[25] Mohamed, I.M., He, J., and Nasr-El-Din, H.A. 2012. Carbon Dioxide Sequestration in Sandstone Aquifers: How Does It Affect the Permeability? In Carbon Management Technology Conference: Carbon Management Technology Conference. ISBN 1613991797.

[26] Mohamed, I.M., He, J., and Nasr-El-Din, H.A. 2013. Experimental Analysis of CO2 Injection on Permeability of Vuggy Carbonate Aquifers. Journal of Energy Resources Technology 135 (1): 013301.

[27] Mohamed, I.M., He, J., and Nasr-El-Din, H.A. 2012. Permeability Reduction During CO2 Injection in Sandstone Aquifers: Lab and Simulation Studies. Canadian Energy Technology and Innovation Journal 1 (2): 36-44.

[28] Nasr-El-Din, H., Mahmoud, M.A.N.-E.-D., De Wolf, C.A. et al. 2012. Process to Fracture a Subterranean Formation Using a Chelating Agent. In: US Patent App. 14/124,924.

[29] Wennberg, K.E., Batrouni, G., and Hansen, A. 2000. Modelling Fines Mobilization, Migration and Clogging. 16th World Petroleum Congress, 11-15 June, Calgary, Canada. DOI: 10.2118/30111-ms.

[30] Xuejun, H., He, J., and Tenfei, S. 2015a. Analysis of the Critical Buckling Loads and Contact Loads on Coiled Tubing String in a Vertical Microhole. Chemistry and Technology of Fuels and Oils 51 (3): 308-319.

[31] Xuejun, H., He, J., and Tenfei, S. 2015b. Analysis on Design of Coiled Tubing Sliding Drilling Electronic Control Tractor with Hydraulic-Driven in Microhole. Electronic Journal of Geotechnical Engineering 20 (10): 4333-4347.

[32] Jiafu Yan, Haiwen Wang, Jia He, Xiaomeng Huang, Huixin Liu. 2009. Fracturing string packer packer Comparison Analysis. Well Testing 18 (4), 6-11.

\section{AUTHORS' BIOGRAPHY}

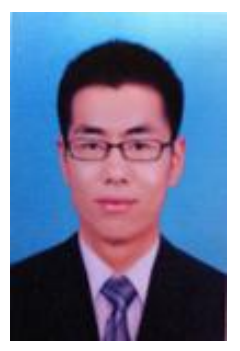

Bin Yang, is a senior reservoir engineer in LiaoDong Field Operations LLC (CNOOC TianJing Branch). He graduated in China University of Petroleum (East China) with a Bachelor degree. He has extensive work experience in reservoir dynamic analysis and development.

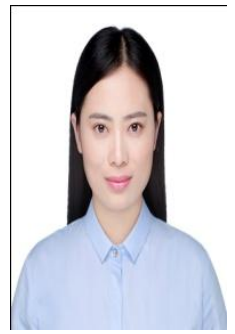

Jie Xiao, is a senior research engineer in Holding Energy Petroleum Engineering (BeiJing) Co.,Ltd. Her research interests include reservoir engineering, production engineering, and oilfield chemistry. She has published $3+$ journal papers and presented $5+$ technical papers. 
Bin Yang et al.

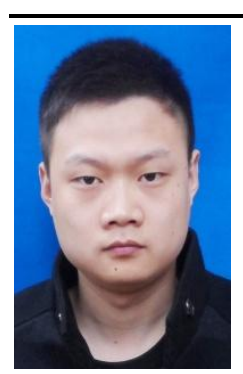

Jing Li, is a graduate student in Northeast Petroleum University and his research interest is enhanced oil recovery technologies.

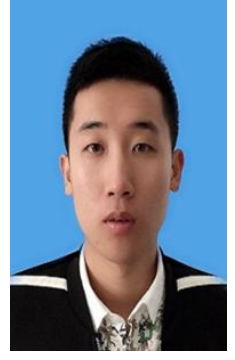

Chengliang Li, is a graduate student in Northeast Petroleum University and his research interest includes oilfield development and simulation studies on enhanced oil recovery.

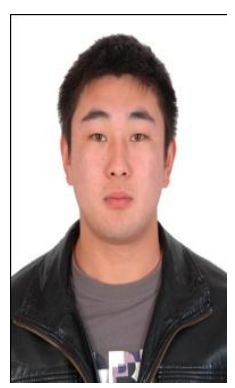

Hongzhi Shao, is a graduate student in Northeast Petroleum University and his research interest includes horizontal drilling technology and oilfield development. He has been worked in Xinjiang Beiken Energy LLC. 